\title{
Lola Zieta Azelien
}

\author{
Adib Rifqi Setiawan \\ $\Lambda$ lobatnic Research Society $(\Lambda \mathrm{RS})$ \\ J1 Kudus - Colo, km. 19, Pandak 001/003, Colo, Kudus, 59353, Indonesia \\ adibrifqisetiawan@gmail.com
}

\begin{abstract}
Abstrak
Esai ini bertujuan untuk mendapatkan profil Lola Zieta Azelien berdasarkan tuturan yang disampaikan secara lisan olehnya, kemudian mendeskripsikan konsep modal erotis yang digunakan olehnya dalam karier sebagai model.
\end{abstract}

Kata-kata Kunci : Lola Zieta Azelien; Modal Erotis; Model;

\section{Pengantar}

Perkembangan seni fotografi dan industri busana membuat kebutuhan terhadap model (peragawati) ikut terdongkrak. Model menjadi bidang yang mulai digeluti oleh banyak pihak. Tak sekadar sebagai pekerjaan sampingan, melainkan menjadi karier utama seseorang. Bahkan beberapa model bisa membuka lapangan pekerjaan sebagai tambang uang. Model merupakan pekerjaan yang bergerak dalam bidang jasa untuk menampilkan busana dan/atau menjadi objek pemotretan (Setiawan, 2018). Seperti jenis pekerjaan lain, menjadi model juga memiliki keuntungan dan kerugian. Tak dimungkiri memang menjadi model bisa memberi kegembiraan tersendiri, terlebih jika dilakoni sepenuh hati. Namun tak disangkal pula bahwa banyak tantangan yang dihadapi, apalagi kalau sudah berada pada posisi tinggi.

Keuntungan menjadi model, antara lain, menjadi panutan dalam penampilan. Penampilan badan seorang modelbiasa dianggap sebagai acuan. Karena menjadi acuan, model mudah dikenal oleh banyak kalangan. Dikenal banyak kalangan memudahkan model untuk meluaskan pergaulan, menambah wawasan, hingga menggunakannya sebagai sarana meraih penghasilan. Keuntungan tentu sebanding dengan kerugian yang didapatkan (Setiawan, 2018). Anggapan sebagai acuan dalam berpenampilan membuat model seakan dituntut untuk senantiasa memperhatikan penampilan badan. Perhatian dapat berupa perawatan fisik, pemilihan busana yang dikenakan, hingga perilaku ketika mengenakan busana tertentu. Ditambah dengan tingkat keterkenalan yang tinggi, tuntutan tersebut membuat perjalanan pribadi model cukup terganggu.

Keuntungan dan kerugian tersebut disadari dengan baik oleh Lola Zieta Azelien, perempuan kelahiran Blitar, Indonesia. Lola, sapaannya, termasuk perempuan inspiratif berusia muda. Pasalnya, Lola terbilang total dalam mendalami kesenangannya. Melalui esai ini, kami mendeskripsikan profil Lola Zeita Azelien yang disusun berdasarkan wawancara dengan Lola Zieta Azelien pada 6 September 2018 (Froyonion, 2018). Profil tersebut menjadi dasar ulasan konsep erotic capital dari Catherine Hakim yang terdapat dalam perjalanan karier Lola Zieta Azelien sebagai model (Hakim, 2010). 


\section{Profil Lola Zieta Azelien}

Lola Zieta Azelien yang lahir pada 17 Maret 1995 dibesarkan dalam keluarga kelas menengah. Sejak kecil dirinya sudah jatuh hati dengan dunia gambar. Sampai akhirnya Lola memilih Desain Komunikasi Visual di Institut Seni Indonesia Yogyakarta untuk melanjutkan pendidikan formal sekaligus mendalami ranah visual secara formal. Dunia cosplay (Indonesia: permainan kostum, Jepang: コスプレ/Kosupure) mulai menarik hati Lola.

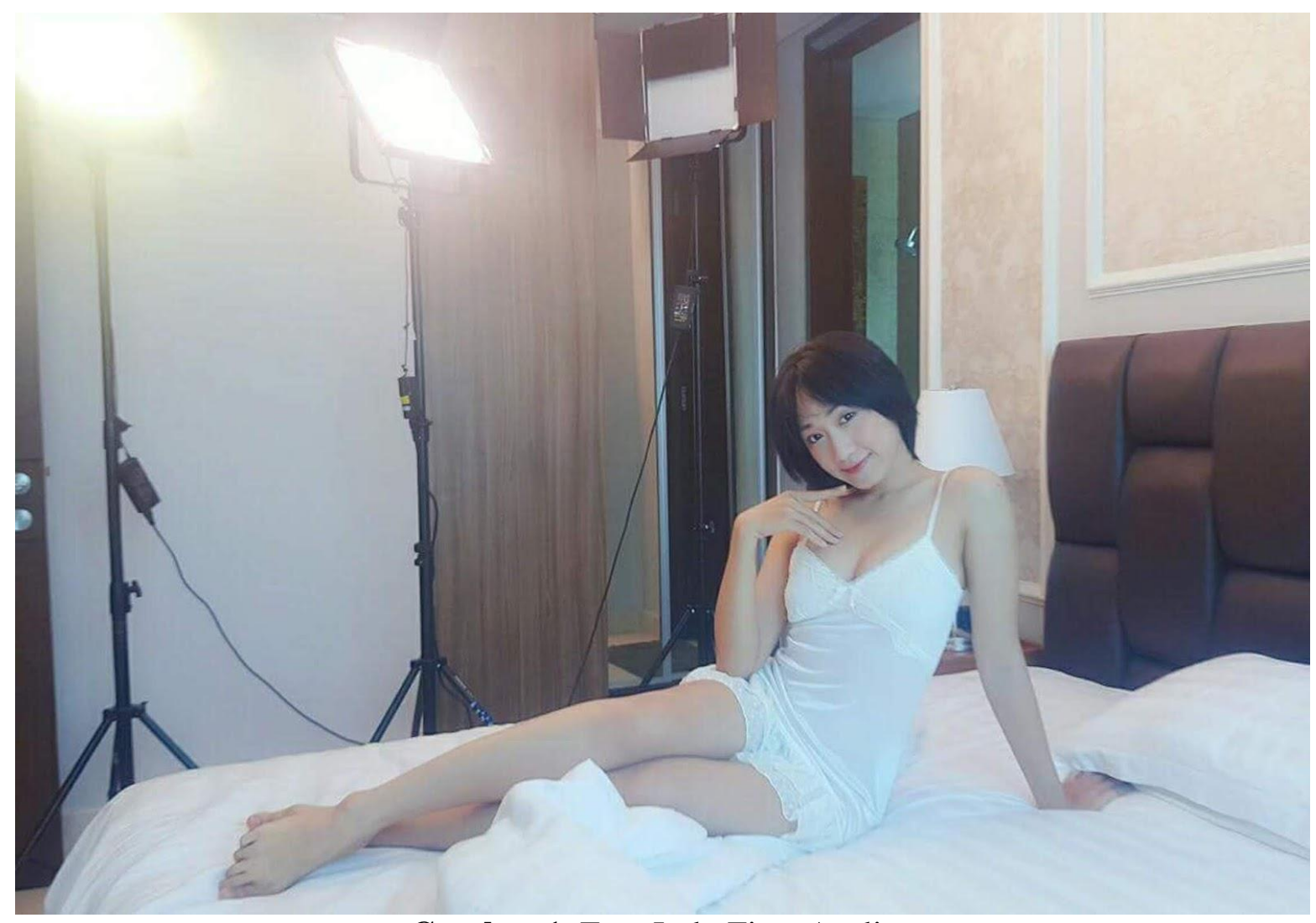

Gambar 1. Foto Lola Zieta Azelien

Cosplay adalah kegemaran mengenakan pakaian beserta hiasan dan riasan seperti yang dikenakan tokoh-tokoh dalam anime, manga, dongeng, permainan video, dan film kartun (Stuever, 2000). Pelaku permainan kostum disebut pemain kostum/cosplayer. Buat sebagian orang, menjadi cosplayer adalah kegemaran yang menyusahkan. Kudu berusaha keras untuk mencari kostum yang sesuai dengan diri dan karakter yang diperagakan. Sudah begitu harus susah payah agar dapat memeragakan karakter-karakter sembari berjalan di antara keramaian. Walakin buat sebagian lain, cosplay dirasa sebagai kegiatan yang memberi kepuasan tersendiri.Bahkan tak sedikit yang melakukannya sebagai jalan untuk bisa terkenal sekaligus memberi keuntungan finansial. Lola termasuk dalam himpunan yang tak sedikit itu.

Kakak dari dua adik lelaki ini memulai kegemaran sebagai cosplayer sejak 2013. Sekarang, cosplay sudah menjadi bagian dari perjalanan hidupnya. Catatannya sebagai cosplayer tak bisa dipandang setengah mata. Sudah puluhan pop culture event diikuti oleh Lola. Misalnya Indonesia Comic Con, Anime Festival Asia, Ennichisai, dan CLAS:H. Bahkan Lola pernah mewakili Indonesia dalam acara Tokyo Game Show 2016. 
Lola terbilang memiliki totalitas sebagai cosplayer. Meskipun mulanya perekonomian Lola tak bisa disebut menguntungkan, dia tak ragu untuk menggelontorkan banyak uang. Paling sedikit Lola memerlukan Rp.800.0000 untuk memeragakan satu karakter. Uang sejumlah itu dipakai untuk menyewa wig, sepatu, kostum, soft lens, dan aksesori. Walau begitu, Lola mengaku ada beberapa hal yang membuatnya tak senang ketika menjadi cosplayer, seperti ketika harus memakai soft lens lebih dari tiga jam. Lola tak senang dengan hal ini karena membuat matanya tak nyaman bahkan sempat mengalami iritasi. Kulit kepalanya juga pernah lecet karena wig.

Sebagai cosplayer, Lola memiliki beberapa sosok role model. Mulai dari Jannet Incosplay, Alyson Tabbitha, Irine Meier, Petrovich Gesha, Elena Samko, Gym Cosplay, M Mellu, Fink Fink, Oniksiya, hingga Non Summerjack. Dari semua karakter yang pernah diperagakan oleh Lola, dirinya mengaku paling senang menjadi perempuan petarung, seperti dimainkan oleh Tifa Lockhart (Final Fantasy VII), Mikasa Ackerman (Attack on Titan), Jun Kazama (Tekken), Mai Shiranui (King of Fighter), Nico Robin (One Piece), dan Motoko Kusanagi (Ghost in the Shell). Nama terakhir tersebut dianggap paling sulit diperagakan oleh Lola.

Kesenangan menjadi perempuan petarung membuat Lola berkhayal bisa punya kekuatan dari Guts, salah satu karakter dalam Berserk, anime kesukaannya. Kesenangan dan khayalan ini memang didasari naluri Lola yang senantiasa ingin menerjang setiap penghalang kemauannya untuk terus maju mewujudkan impian. Tak heran kalau Lola belajar teknik bela dari. Bahkan meski memiliki ukuran kesintalan badan menawan, Lola enggan dijuluki seksi. Dirinya mengaku lebih senang dibilang sebagai "a boy with a pair of boobs".

\section{Alasan Memilih Karier sebagai Model}

Lola tak lelah menekuni dunia visual bukan semata memuaskan hasratnya, tidak juga sekadar menggembirakan orangtua dan kedua adiknya. Namun, untuk memberi motivasi dan inspirasi buat sesama manusia biasa, khususnya orang yang merasakan hidup dengan ekonomi yang terbilang 'pas-pasan'.

Orangtua Lola bekerja sebagai penjual lele dengan lapak yang kecil. Penghasilannya memang cukup untuk memenuhi kebutuhan pokok harian, tapi perlu memutar otak agar bisa menekan pengeluaran. Pengalaman hidup seperti ini membuat perempuan yang gemar mendengarkan musik era 1950-1980-an ini merasa terpanggil untuk ikutserta berusaha mencukupi kebutuhan keluarga. Panggilan inilah yang membuat Lola tak ragu melangkah sebagai model fotografi.

Pada awalnya, banyak orang yang hadir sebagai perintang pilihan Lola tersebut. Malah ketika Lola mulai melangkah, tak sedikit orang dekat yang menjauh darinya. Bahkan orangtua pun sempat tak menyarankan Lola menjadi model. Hal yang paling diingat Lola ialah tatkala orangtua merasa menyesal hidup dalam kemiskinan. Sehingga mereka merasa telah bersalah karena menyebabkan Lola kini menjadi model yang lekat dengan kesan seksi.

Itu semua tak menyurutkan semangat Lola. Lola merasa saat ini, seperti inilah jalan yang harus ditempunya. Pada masa depan, entahlah. Buatnya yang penting kehadirannya bisa membantu keluarga. Urusan bahwa status sebagai model dapat membuatnya menyenangkan hasrat orang lain, terutama lelaki, hanyalah bonus semata. 
Lola adalah salah satu manusia yang berani berunjuk rasa (expression) dengan cara yang bisa dilakukannya. Keberanian berunjuk rasa menjadi satu hal yang memang selayaknya dilatih sejak masa balita (Setiawan, 2017). "Express yourself!"tutur Madonna melalui Express Yourself, lagu yang dirilis 9 Mei 1989 dalam album Like a Prayer. Keberanian berunjuk rasa memberi semangat agar tak ragu mengungkapkan perasaan dengan penuh yakin diri (confident). Yakin diri menjadi pondasi penting dalam membentuk jiwa yang rendah hati (humble). Manusia yang piawai berunjuk rasa memiliki dua sisi berkelindan ini: yakin diri dan rendah hati (Setiawan, 2018). Meski seringkali yakin diri dilihat sebagai arogansi dan rendah hati dinilai sebagai wujud rendah diri.

Walau unjuk rasanya menggembirakan rasa manusia lainnya, perempuan yang baru mulai memakai miniset sejak ... ini tetaplah manusia biasa. Lola butuh makan, minum, maupun tidur, juga bisa berpeluh lelah, berkeluh kesah, berkeruh amarah, merasa bad mood, bahkan minder laiknya manusia pada umumnya. Alhasil, kepiawaian Lola dalam berunjuk rasa dengan berbagai cara tetap disertai pembawaan diri dalam menjalani keseharian sepertihalnya manusia biasa. Lola tak pernah merasa muruahnya merendah dengan mengungkapkan bahwa dirinya adalah penggemar berat Berserk alias mengagumi karya orang lain. Dirinya juga biasa saja saat berinteraksi dengan orang yang menyatakan sebagai penggemar beratnya.

Di luar sisi sebagai workaholic, Lola tetap bersemangat saat terlibat obrolan, membaca buku, serta jalan-jalan. Sembari mengayuh perjalanan selaras nuraninya, dia pun terus melantan rasa cinta pada orangtua, keluarga, sahabat, gurunya, dan orang-orang dekatnya. Lola memang mulai menjadi sosok yang dikagumi banyak orang hingga mendapat semat sebagai panutan. Sebagai panutan, Lola tak lelah berusaha untuk ikutserta memberikan penghiburan dan menyuntikkan pengharapan.

Lola tak setengah hati menggeluti dunia visual, untuk melampiaskan hasrat seni maupun meraih keuntungan finansial. Dengan tetap menyadari keuntungan dan kerugian yang didapatkan, Lola terus menjalani dengan penuh gairah membuncah. Sekarang penggemar musik 1950-80 an ini seakan mengayuh perjalanan yang membuat namanya memiliki harga jual. Kehadirannya pun dapat memiliki nilai komersial. Keadaan yang demikian tentu memudahkannya untuk ikutserta dalam berbagai kegiatan sosial.

\section{Pemanfaatan Erotic Capital dalam Karier Lola Zieta Azelien}

Tak dimungkiri bahwa kecantikan turut berperan dalam perjalanan Lola. Karena kecantikan ini pula Lola banyak mudah mendapatkan cibiran, seperti 'modal cantik doang'. Pertanyaannya, salahkah menjadi perempuan cantik? Sebagian orang mungkin akan menjawab iya (Zein \& Setiawan, 2019). Naomi Wolf menuturkan bahwa kecantikan adalah mitos yang diciptakan industri untuk mengeksploitasi perempuan secara ekonomi melalui produk-produk kosmetik. Pandangan Naomi beserta pendukungnya boleh jadi tidak bisa disalahkan, namun kurang lengkap untuk menjadi genggaman. Pasalnya Naomi tak mementingkan paras cantik sebagai salah satu modal untuk perempuan, seperti diungkapkan oleh Catherine Hakim melalui konsep erotic capital (modal erotis). Erotic capital merupakan kombinasi dari daya tarik fisik, estetik, visual, sosial, dan seksual yang dimiliki seseorang untuk menarik orang lain (Hakim, 2010). Ada enam bagian dalam erotic capital, kecantikan adalah salah satunya. Sepertihalnya jenis modal lain, erotic capital juga dapat diupayakan, kosok bali dengan pandangan yang cenderung menyangka bahwa kecantikan hanyalah ketetapan Tuhan (buat yang percaya Tuhan) atau suatu kebetulan alamiah (buat yang cuma percaya Hukum Alam). 
Cibiran terhadap Lola maupun orang lain yang turut memanfaatkan kecantikan, banyak berpijak dari pandangan yang menyebut bahwa pintar adalah hasil tekun belajar, sedangkan cantik adalah bawaan lahir. Cerdas dianggap sesuatu yang diperoleh lewat kerja keras, sedangkan kecantikan adalah anugerah yang didapat tanpa usaha. Padahal posisinya bisa saja terbalik. Pasalnya faktor genetis pun, terutama dari ibu, berperan penting dalam menentukan kecerdasan seseorang. Sedangkan untuk tampil cantik, seseorang perlu banyak berusaha, mulai dari olah raga, menjaga pola konsumsi, merias wajah, hingga berpikir menentukan pakaian. Tak perlu membutakan mata menyaksikan bahwa orang yang cantik memang kerap mendapat beragam kemudahan. Contoh paling bagus dalam hal ini ialah Maria Yuryevna Sharapova (Maria Sharapova) (Badenhausen, 2016). Pendapatan sebagai model jauh lebih banyak ketimbang menjadi petenis. Maria bahkan masih tetap menambah kekayaan saat diskors gara-gara kasus obat-obatan terlarang. Nilai penting erotic capital setara dengan modal lain seperti ekonomi, sosial, dan budaya.

Pertanyaan selanjutnya, mengapa kita tampak enggan mengapresiasi kecantikan perempuan sepertihalnya kecerdasan? Ketika ada perempuan dandan, dibilang menghabiskan waktu tak berguna. Walakin ketika membaca buku, disangka waktu diisi dengan kegiatan bermanfaat. Perempuan yang berusaha menunjukkan kecantikan malahan tak jarang otomatis dianggap bodoh. Pekerjaan yang menjual badan perempuan, seperti modelling, diberi stigma sebagai pekerjaan hina. Lebih menyesakkan lagi, ketika ada perempuan cantik ingin menikahi lelaki kaya dilabeli 'matre' yang mengkhianati kesucian cinta dalam perkawinan. Padahal, alasan di balik julukan 'matre' ini adalah bahwa lelaki harus mendapatkan kenikmatan yang mereka inginkan dari perempuan secara gratis, terutama seks (sex). Kecantikan dan upaya mempercantik diri dianggap sebagai tindakan tak baik. Para peserta kontes kecantikan, misalnya, mendapatkan banyak cibiran. Kecerdasan dan kecantikan dilihat sebagai dua hal bertentangan yang tak mungkin dipadukan oleh perempuan. Perempuan yang memiliki keduanya, tidak diizinkan untuk menggunakan semuanya, hanya boleh memaksimalkan kecerdasan saja. Mengapa oh Menyapa? Whyyy?

Dengan memperhatian perdebatan wacana pemanfaatan badan perempuan tersebut, Lola patut diapresiasi semadyana sebagai perempuan yang menggunakan kecerdasan dan kecantikan. Sah-sah saja kalau Lola rajin merawat badan, terutama payudara dan pantat, bagian yang memiliki daya pikat kuat dalam merangsang gairah seks lelaki (Setiawan, 2018). Seks terbilang nafsu yang paling sosial (Setiawan, 2018). Tanpa memperhitungkan moral, secara naluriah kita bisa turut bergembira menyaksikan orang lain yang sedang memenuhi nafsu seksnya. Kita punya hasrat kesenangan walaupun sekadar untuk menontonnya. Itulah kenapa ada pornografi, yang melahirkan industri seperti blue film (BF) dan majalah dewasa dengan omzet besar.

Seks berbeda dengan nafsu lain, misalnya nafsu makan. Adakah orang, terutama lelaki, yang sanggup suntuk berjam-jam menyaksikan tayangan dengan sajian berupa adegan-adegan orang sedang makan bakwan biarpun orang itu adalah Cania Citta Irlanie? Adakah media pendulang iklan yang menjebak pengunjung dengan gambar Oza Kioza sedang mangap ngemplok cilok? Saking sosialnya nafsu yang satu itu, ia jadi begitu canggih buat menyedot perhatian. Ia jadi empuk sebagai bahan berita dengan judul-judul menggemaskan. Ia juga legit buat stok pengalihan isu, yang bisa dengan gampang ditembakkan sewaktu-waktu. Sebab, kabar terkait seks tidak cuma memberikan informasi, walakin memberdayakan imajinasi. Lola menyadari sisi ini, mengerti hal ini. Tak risau dengan segala caci-maki maupun puja-puji, dirinya berusaha memanfaatkannya memenuhi kebutuhan diri. 


\section{Penutup}

Lola Zieta Azelien yang lahir pada 17 Maret 1995 dibesarkan dalam keluarga kelas menengah. Dasar terkuat dari diri Lola untuk menjadi model ialah fakta bahwa sejak kecil dirinya sudah jatuh hati dengan dunia gambar. Sebagai model, Lola tak ragu untuk memanfaatkan penampilan badan karena menyadari bahwa tubuh perempuan memiliki daya pikat kuat dalam merangsang gairah seks lelaki.

\section{Referensi}

Badenhausen, K. (2016, Maret 6). How Maria Sharapova Earned \$285 Million During Her Tennis Career. Dipetik September 7, 2018, dari Forbes:

https://www.forbes.com/sites/kurtbadenhausen/2016/03/08/how-maria-sharapovaearned-285-mill-during-her-tennis-career/

Froyonion. (2018, September 7). LOLA ZIETA DAN LIKA LIKU KEHIDUPANNYA | Froyonion Meets. Dipetik September 7, 2018, dari YouTube: https://youtu.be/qE1sH3i2h0s

Hakim, C. (2010, Oktober). Erotic Capital. European Sociological Review, 26(5), 499-518.

Setiawan, A. R. (2017, Februari 15). Butcah Chuniez: Puzzle Persinggungan Perjalanan dengan Eny Rochmwati Octaviani. Dipetik September 7, 2018, dari Alobatnic: https://alobatnic.blogspot.com/2017/02/thata.html

Setiawan, A. R. (2018, Maret 5). Breast Capital. Dipetik September 7, 2018, dari Alobatnic: https://alobatnic.blogspot.com/2018/03/breastcapital.html

Setiawan, A. R. (2018, Maret 1). Ki Oza Kioza. Dipetik September 6, 2018, dari Alobatnic: https://alobatnic.blogspot.com/2018/03/roza-lailatul-fitria-oza-kioza.html

Setiawan, A. R. (2018, Januari 1). Pantat Perekat Umat. Dipetik September 6, 2018, dari Alobatnic: https://alobatnic.blogspot.com/2018/01/pantat-perekat-umat.html

Setiawan, A. R. (2018, April 2). Rosa Amalia Iqony. Dipetik September 6, 2018, dari Alobatnic: https://alobatnic.blogspot.com/2018/04/rosa-amalia-iqony.html

Setiawan, A. R. (2018, Maret 9). Venice Min. Dipetik September 7, 2018, dari Alobatnic: https://alobatnic.blogspot.com/2018/03/venice-min.html

Stuever, H. (2000, Februari 14). What Would Godzilla Say? Dipetik September 7, 2018, dari Washington Post: https://www.washingtonpost.com/wp-srv/style/feed/a494272000feb14.htm?noredirect=on

Zein, L. F., \& Setiawan, A. R. (2019, Maret 19). Salahkah Menjadi Perempuan Cantik? Laila Academy. 